\title{
Research in neurological diseases: lost in translation?
}

\author{
John W Griffin
}

The brain sciences are on a roll. Young scientists are choosing the neurosciences for their careers, basic discoveries are accruing at a breathtaking rate, and the relevance of these discoveries to neurological disease is increasing. Accordingly, the governmental funding base for brain research has substantially expanded in the US and other countries in the past decade.

Nevertheless, there is palpable restlessness among disease advocacy groups, philanthropists and neurological investigators. For investigators, the problems are heightened by relative reductions in government funding, notably at the NIH. Among advocacy groups, the mood is one of impatience and frustration; effective treatments for the most prevalent diseases are not emerging at the rate that might have been predicted from the level of investment.

Many investigators and advocacy groups acknowledge deep structural problems in translational research. Government research agencies are viewed as slow in turnaround, bureaucratic, lacking the will to support innovation, and more comfortable supporting incremental research. The pharmaceutical industry is weighed down by concerns about the size of the market, by internal bureaucracies, and by the increasing regulatory burden in drug development. Small biotech companies are perceived as willing to take on 'orphan' diseases, and as possessing innovative energy. Limited capitalization, however, can tempt these companies into premature clinical trials, and anything less than a dramatically positive outcome can lead to withdrawal of new financial support.

Universities are seen as having scale, depth and sustainability, but they often depend on slow grant-based funding mechanisms, and have cumbersome, divisive organizations. Space is often assigned in an inflexible, departmentally driven allocation system. University technology offices can generate legalistic and bureaucratic entanglements that slow current discovery.

The time is right for experimental solutions to these problems. The Public Policy Symposium

\section{Among \\ advocacy \\ groups, the \\ mood is one \\ of impatience \\ and frustration; \\ effective \\ treatments... \\ are not \\ emerging at \\ the rate that \\ might have \\ been predicted}

JW Griffin is the

Editor-in-Chief

of Nature Clinical

Practice Neurology, and Director of

the Department

of Neurology and

Neurologist-in-Chief

at Johns Hopkins

University School of

Medicine, Baltimore,

$M D, U S A$.

\section{Competing interests}

The author declared he has

no competing interests.

www.nature.com/clinicalpractice doi:10.1038/ncpneuro0123 of the 2005 American Neurological Association highlighted several such experiments, including The Robert Packard Center for ALS Research, the $A B C^{2}$ Foundation for brain tumor research, the QB3 program for quantitative biology at the University of California, and the advent of venture philanthropy.

Non-governmental funding sources are beginning to ask how they can accelerate the translational progress without diluting their goals. To have the greatest impact on neurological disease, they might consider the following strategies:

1. Insisting that some portion of gifts be spent directly on research rather than being endowed, with commitments to ongoing fundraising to leverage the impact of gifts.

2. Expecting recruitment of the best people into project-focused teams to tackle key research targets, creating a mix that crosses departmental and institutional boundaries.

3. Mandating participation of recruited investigators in regular group meetings, and withdrawing funds for non-participation.

4. Focusing on speed in answering the "next questions' by setting aside flexible funds that can be directed promptly.

5. Coupling acceptance of funds with acceptance of real benchmarking of progress.

6. Developing non-academic 'swat teams' comprising skilled scientists who are not on academic ladders.

7. Requiring unfettered exchange of ideas and data within research groups, and exploring an open-source model to provide data to the broader community.

8. Developing new intellectual-property approaches that do not delay progress.

Such organizational innovations can be used to merge the best features of research by universities, pharmaceutical companies and biotech companies. Patients, advocates, philanthropists, investors and investigators can all look forward to the advent of new models of translation in neurology. 